\title{
Differential expression of microRNAs in a hyperoxia-induced rat bronchopulmonary dysplasia model revealed by deep sequencing
}

\author{
D. $\mathrm{Li}^{1^{*}}$, H. Cheng ${ }^{2 *}$ L. Chen ${ }^{2}$ and B. Wu ${ }^{3}$ \\ ${ }^{1}$ Longgang ENT Hospital, Institute of ENT and Shenzhen Key Laboratory of \\ ENT, Shenzhen, China \\ ${ }^{2}$ Institute of Respiratory Diseases, Shenzhen People's Hospital, The Second \\ Clinical Medicine College of Jinan University, Shenzhen, Guangdong, China \\ ${ }^{3}$ Children's Medical Center, China Medical University Shenzhen hospital \\ (Guangming), Shenzhen, Guangdong, China \\ Corresponding author: H. Cheng \\ B. $\mathrm{Wu}$ \\ E-mail: chenghanrongsz@163.com; \\ wubenqing783@126.com \\ *These authors contributed equally to this study
}

Genet. Mol. Res. 20 (2): gmr18751

Received October 21, 2020

Accepted May 11, 2021

Published May 31, 2021

DOI http://dx.doi.org/10.4238/gmr18751

\begin{abstract}
We examined the biological roles of microRNAs (miRNAs) in the pathogenesis of bronchopulmonary dysplasia (BPD). Neonatal rats were randomly assigned to hyperoxia $\left(85 \% \mathrm{O}_{2}\right)$ and normoxia $\left(21 \% \mathrm{O}_{2}\right)$ groups, and each group had eight neonatal. Twenty differentially expressed miRNAs were identified by deep sequencing, of which 10 were up-regulated and 10 were down-regulated in the hyperoxia group. A total of 5,794 molecular related to gene ontology functions were enriched, including cell location and biological processes. rno-miR-29b-3p were up-regulated, and rno-miR-322-5p and rno-miR335 were down-regulated in the hyperoxia sample based on quantitative real-time PCR. In conclusion, BPD appears to be caused by activation of extracellular matrix -receptor interaction, cytokine-cytokine receptor interaction, RNA transport, cell cycle, and cell adhesion molecule pathways. These miRNAs may play a role in the occurrence and development of BPD. Our study provides new insight into the biological processes of BPD.
\end{abstract}


Key words: Bronchopulmonary dysplasia; Chronic lung disease; Inflammatory; miRNA; Deep sequencing

\section{INTRODUCTION}

Premature babies are born with immature lungs and consequently require respiratory support. Hyperoxia exposure contributes to the development of bronchopulmonary dysplasia (BPD), although it is necessary to maintain adequate oxygenation (Kobaly et al., 2008). Currently, BPD is defined as infants who greater than 28 days, and/or 36 weeks of gestational age still require oxygen supplementation (Niedermaier et al., 2015). Pathologically, BPD is characterized by impaired alveolar and vascular development, and interstitial fibrosis (Kobaly et al., 2008). Although preterm infant mortality has declined over the past 20 years, the incidence of BPD has increased (Niedermaier and Hilgendorff, 2015). Hyperoxia exposure in a newborn rat causes inflammation, alveolar development deficits and interstitial fibrosis, which is similar to infants with BPD (Choi et al., 2015; Zhu et al., 2015).

MicroRNAs (miRNAs) are a class of small non-coding RNAs that can posttranscriptionally regulate the expression of protein-coding genes by reducing the mRNA stability of the targeted genes (Yang et al., 2013; Ameis et al., 2017). Recent studies have revealed that miRNAs are involved in various biological processes, such as tumorigenesis, infection, fibrosis, and respiration. There is increasing evidence indicating that miRNAs may be involved in the pathophysiology of BPD (Ameis et al., 2017). Durrani-Kolarik et al. (2017) showed that miR$29 \mathrm{~b}$ decreased the expression of matrix proteins, which led to the improvement of alveolarization in mice exposed to maternal inflammation and neonatal hyperoxia. Syed et al. (2017) demonstrated that hyperoxia induced miR-34a-mediated injury via angiopoietin-1 in neonatal lungs. The study of Lal et al. (2018) showed that exosomal miR-876-3p predicted and protected against severe BPD in extremely premature infants. Additionally, Zhang et al. (2019) identified the hypoxia-inducible factor 1-alpha/miR-30a/Snail 1 axis as an important signaling pathway associated with the regulation of hyperoxic lung injury. Thus, the identification of novel miRNAs involved in the pathophysiology of BDP may be important for the development of novel therapies for BPD.

We examined miRNA expression levels in the lung tissues of newborn rats exposed to hyperoxia or normoxia for 14 days by RNA sequencing. The expression levels of the differentially expressed miRNAs was further examined to elucidate the underling roles of miRNA expression during BPD development. The possible functions and biological mechanisms of the target genes regulated by these miRNAs were also explored using database prediction and experimental validation.

\section{MATERIAL AND METHODS}

\section{Animal model and tissue specimens}

We used a newborn rat model of BPD; 64 newborn Sprague-Dawley (SD) rats were randomly assigned to a hyperoxia group (exposure to $85 \% \mathrm{O}_{2}$ ) from day of birth or normoxia group (exposure to $21 \% \mathrm{O}_{2}$ ) based on our previous studies (Cheng et al., 2020). Foster rats in a hyperoxic chamber were rotated daily to avoid oxygen toxicity. Water and food were freely available. After exposure to hyperoxia or normoxia, rats from the two groups were anesthetized on days $1,3,7$, and 14, and whole lungs were collected. The entire upper left lung was immersed 
in $4 \%$ formaldehyde and embedded in paraffin 24 hours later. The left lower lung and right lung were frozen in liquid nitrogen and stored at $-80^{\circ} \mathrm{C}$ until use. Mature SD rats were purchased from the department of Animals, Experimental Center, Southern Medical University (Guangzhou, China). All animal experiments were approved and supervised by the Ethics Committee of Animals, Shenzhen Peoples' Hospital.

\section{Morphometric analysis}

Lungs were fixed with $4 \%$ paraformaldehyde, embedded in paraffin, and serial sections (5 $\mu \mathrm{m}$ each) were cut along the sagittal plane. Lung sections were stained with hematoxylin and eosin (H\&E), and representative microphotographs were taken at $400 \times$ magnification. A lung injury scoring system was established before the study (You et al., 2012).

\section{Western blotting}

The expressions of E-cadherin (E-cad), Surfactant protein C (SPC), transforming growth factor beta (TGF- $\beta$ ), alpha smooth muscle actin ( $\alpha$-SMA) were measured by Western blot. Total protein from lung tissues was extracted by radioimmunoprecipitation assay lysis buffer Extraction Kit (Beyotime Biotechnology Co. Ltd, Shanghai, China). After sodium dodecyl sulfate polyacrylamide gel electrophoresis (SDS-PAGE), the separated proteins were transferred to a polyvinylidene fluoride membrane, and 10\% skim milk was used to block the membrane and incubated with various antibodies overnight: (anti-E-cad, anti-SPC, anti-TGF- $\beta$, anti- $\alpha$-SMA, (Santa Cruz Biotechnology, CA, USA) and anti-actin (Cell Signaling Technology, USA). The membrane was then incubated in secondary antibody for $4 \mathrm{~h}$, washed in TBST buffer three times, developed with enhanced chemiluminescence substrate (Pierce ${ }^{\mathrm{TM}}$ Fast Western Blot Kit; Thermo Biotechnology) and exposed to X-ray film. Image analysis system (Image-Pro Plus Version 6.0) was used to evaluate integrated density values and standardized to $\beta$-actin.

\section{RNA sequencing}

Right lung lobes were collected from the hyperoxia and normoxia groups on day 14 . Each group included six samples. TRIzol reagent (Invitrogen, USA) was used to isolate RNA, according to the manufacturer's protocol. RNA concentration was measured using a microscope spectrophotometer (GeneQuant 1300). Agarose gel electrophoresis was applied, and RNA integrity was assessed with the RNA Nano 6000 assay kit (Agilent Technologies, USA). Then a PAGE gel was used to separate and recover small RNAs of 18-30 nt. Recovered small RNA was mixed and centrifuged in a $3^{\prime}$ connection system at a suitable temperature and a $5^{\prime}$ connector added. Then reverse transcription was used, and finally amplificated by PCR, recovered and purified by PAGE gel. An aliquot of $1 \mu \mathrm{g}$ RNA from each sample was used according to the NEBNext ${ }^{\circledR}$ Multiplex Small RNA Library Prep Set for Illumina ${ }^{\circledR}$. The constructed libraries were tested with the Agilent 2100 Bioanalyzer and ABI StepOnePlus Real-Time PCR System, and then deep sequenced with the Illumina HiSeqTM2000. The miRNA samples were subjected to SE50 sequencing according to the HiSeq SR Cluster Kit v4 cBot instructions and the Hiseq2500 sequencer operating instructions. The data was used in the following analysis to detect gene expression, variable splicing, new transcript prediction and annotation, and gene fusion based on the quality control established before the studies (Audic et al., 1997).

\section{Quantitative real-time PCR (qRCR)}


To confirm the reliability and accuracy of the RNA-seq data, four BPD-related target miRNA and their target genes were selected according to the criteria (different expressions $\geq 2$ times, Q-value (false discovery rate $(\mathrm{FDR})$ ) $\leq 0.001$, Kyoto Encyclopedia of Genes and Genomes (KEGG) pathways, and Gene Ontology (GO)). The primers are shown in Table 1.

Table 1. The primer sequences for miRNAs and mRNAs in the qPCR validation studies.

\begin{tabular}{|c|c|c|}
\hline Primer & Sequence & (bp) \\
\hline General R primer & GTGCAGGGTCCGAGGT & \\
\hline rno-miR-29b-3p-RT & GTCGTATCCAGTGCAGGGTCCGAGGTATTCGCACTGGATACGACAACACT & \\
\hline rno-miR-29b-3p-F & GGTAGCACCATTTGAAATCAG & 59 \\
\hline rno-miR-203a-3p-RT & GTCGTATCCAGTGCAGGGTCCGAGGTATTCGCACTGGATACGACCTAGTG & \\
\hline rno-miR-203a-3p-F & GGCTGAAATGTTTAGGACCA & 58 \\
\hline rno-miR-322-5p-RT & GTCGTATCCAGTGCAGGGTCCGAGGTATTCGCACTGGATACGACTCCAAA & \\
\hline rno-miR-322-5p-F & GCAGCAGCAATTCATGTTT & 57 \\
\hline rno-miR-335-RT & GTCGTATCCAGTGCAGGGTCCGAGGTATTCGCACTGGATACGACACATTT & 50 \\
\hline rno-miR-335-F & GGTCAAGAGCAATAACGAAA & 59 \\
\hline rno -U6-RT & AACGCTTCACGAATTTGCGT & \\
\hline rno -U6-F & CTCGCTTCGGCAGCACA & 94 \\
\hline Rat-colla1-F & TGGCAAGAACGGAGATGA & \\
\hline Rat-colla1-R & AGCTGTTCCAGGCAATCC & 100 \\
\hline Rat-Col5al & ACAGCGGTCCCTGACACACCT & 100 \\
\hline Rat-Col5a1-R & GGGGCTGGGTCTGCTCCTCA & 199 \\
\hline Rat-VEGFA-F & CAAACCTCACCAAAGCCAGC & \\
\hline Rat-VEGF-A-R & ACGCGAGTCTGTGTTTTTGC & 187 \\
\hline Rat-HIF-1 $\alpha-F$ & CCTACTATGTCGCTTTCTTGG & \\
\hline Rat- HIF-1 $\alpha-R$ & GTTTCTGCTGCCTTGTATGG & 198 \\
\hline Rat-cyclin D1-F & CCATGCTTAAGACTGAGGAGAC & 357 \\
\hline Rat-cyclin D1-R & TGAGCTTGTTCACCAGAAGC & 351 \\
\hline Rat-FGF-16-F & GAGGAGAGCT-GTTTGGATCG & \\
\hline Rat-FGF-16-R & GGGTGAGCCGTCTTTATTCA & 155 \\
\hline Rat--RASA1-F & CTGGAGATTATTCCCTGTATTTTCG & 142 \\
\hline Rat-RASA1-R & TGTTCTTTCCGATAGTGGTCTATGA & \\
\hline RAT-Fam107b-F & GCCGAGCCGGACTACATAGA & 99 \\
\hline RAT-Fam107b-R & GTGGAGGTCCTGGTGGTTTC & \\
\hline Rat-GAPDH-F & GCAAGAGAGAGGCCCTCAG & 74 \\
\hline Rat-GAPDH-R & TGTGAGGGAGATGCTCAGTG & \\
\hline
\end{tabular}

TRIzol reagent (Invitrogen. USA) was used to isolate total RNA according to the manufacturer's protocol. Trizol, chloroform and isopropyl alcohol were added, and samples subjected to reverse transcription. qRCR was performed using a fluorescence quantitative PCR instrument (ABI, StepOne Plus). Each sample include three replicates, and glyceraldehyde 3phosphate dehydrogenase (GAPDH) and U6 were used as the internal controls. The program for qRCR was as follows: $95^{\circ} \mathrm{C}$ for $2 \mathrm{~min}$, followed by 40 cycles of $95^{\circ} \mathrm{C}$ for $15 \mathrm{~s}$ and $60^{\circ} \mathrm{C}$ for $30 \mathrm{~s}$. The $2^{-} \Delta \Delta^{\mathrm{Ct}}$ method was used to calculate the relative expression levels. The data were represented as the mean \pm standard deviation values of three replicates.

\section{Statistical analysis}

All data are presented as mean \pm standard deviation. SPSS13.0 software was used for statistical analysis. Inter-group comparisons were conducted using t-tests and multiple group comparisons using one-way analysis of variance (ANOVA). P $<0.05$ iindicated a statistically significant difference. 


\section{RESULTS}

\section{Establishment and validation of hyperoxia BPD rat animal model}

The body weight of the newborn rats was significantly lower in the hyperoxia group than in the normoxia group. The differences between the two groups weresignificant on days $3,7,10$ and $14(\mathrm{P}<0.05)$. The lung injury score significantly elevated on day 3,7 and 14. The western blot results showed that the protein levels of E-cadherin and SPC were significantly down-regulated on day 3, 7 and 14; while the protein levels of TGF-beta and SMA-alpha were significantly up-regulated on day 3, 7 and 14 (Figure 1).
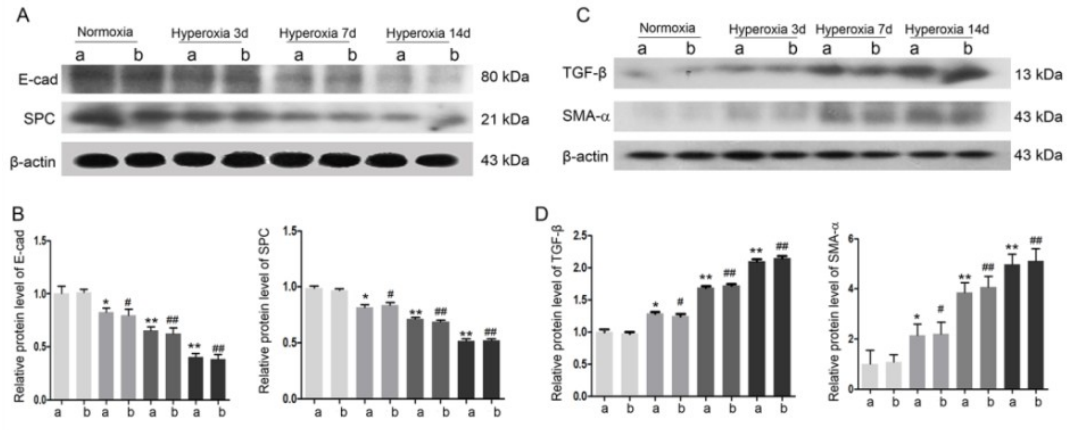

Figure 1. The expression of BPD related marker protein in lung tissue of rats between hyperoxia and normoxia groups detected by western blot. A-B) The expression of E-cadherin and SPC in lung tissues treated with hyperoxia at different time. C-D) The expression of TGF- $\beta$ and SMA- $\alpha$ in lung tissues treated with hyperoxia at different time. $\mathrm{a}$ and $\mathrm{b}$ represent the same group of two samples. ${ }^{*} \mathrm{P}<0.05$ and ${ }^{*} \mathrm{P}<0.01$ vs Normoxia group a, $\# \mathrm{P}<0.05$ and $\# \# \mathrm{P}<0.01$ vs Normoxia group $\mathrm{b}$.

\section{Detection of differentially expression miRNAs between the hyperoxia-induced bronchopulmonary dysplasia and normoxia groups}

The purpose of differential expression analysis was to identify the differentially expressed genes between different samples, in order to help understand the biological mechanisms involved. To identify the miRNAs involved in the lung tissues of hyperoxia group and normoxia group, the expression profiles of the miRNAs were examined after 14 days of hyperoxia exposure. The small RNA size distribution was examined. 22 nucleotide lengths were the most abundant, followed by 21 and 23 nucleotides (Figure 2). A total of 20 different miRNAs were detected in the hyperoxia group and the normoxia group, among which 10 were up-regulated and 10 were down-regulated (Figure 3A and Table 2). Here, the differentially expressed genes were defined as a gene with FDR $\leq 0.001$ and fold change more than 2 fold.
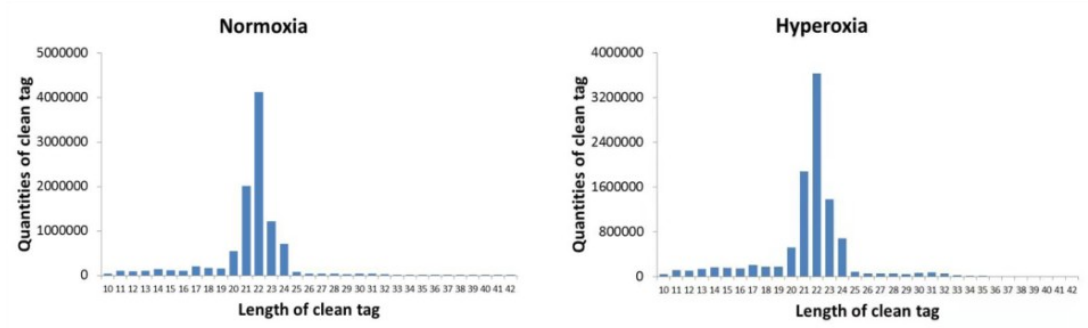

Figure 2. Statistics length distribution of clean tag in normoxia and hyperoxia group. 


\begin{tabular}{|c|c|c|c|c|c|c|c|c|}
\hline miRNA ID & $\begin{array}{l}\text { Normoxia- } \\
\text { Expression }\end{array}$ & $\begin{array}{l}\text { hyperoxia- } \\
\text { Expression }\end{array}$ & normoxia-TPM & hyperoxia-TPM & $\begin{array}{l}\log _{2} \text { ratio } \\
\text { (hyoeroxia/normoxia) }\end{array}$ & $\begin{array}{l}\text { Up-Down } \\
\text { (hyperoxia/normoxia) }\end{array}$ & P-value & FDR \\
\hline $\begin{array}{l}\text { mo-miR-29b- } \\
\text { 3p }\end{array}$ & 34 & 274 & 3.207 .761 .727 & 2.602 .126 .336 & 3.020 .052 .121 & Up & $5.68 \mathrm{E}-55$ & $1.04 \mathrm{E}-53$ \\
\hline $\begin{array}{l}\text { rno-miR-383- } \\
5 \mathrm{p}\end{array}$ & 130 & 565 & 1.226 .497 .131 & 5.365 .698 .467 & 2.129 .222 .124 & Up & 2.14E-78 & $5.29 \mathrm{E}-77$ \\
\hline rno-miR-6327 & 14 & 42 & 1.320 .843 .064 & 3.988 .660 .807 & 159.444 .538 & Up & $2.05 \mathrm{E}-05$ & 0.00010783 \\
\hline $\begin{array}{l}\text { rno-miR-880- } \\
3 \mathrm{p}\end{array}$ & 37 & 93 & 3.490 .799 .526 & 8.832 .034 .644 & 1.339 .188 .325 & Up & $1.27 \mathrm{E}-08$ & $8.68 \mathrm{E}-08$ \\
\hline rno-let-7f-2-3p & 35 & 84 & 330.210 .766 & 7.977.321.614 & 1.272 .517 .285 & Up & $1.72 \mathrm{E}-07$ & $1.05 \mathrm{E}-06$ \\
\hline $\begin{array}{l}\text { rno-miR-153- } \\
3 \mathrm{p}\end{array}$ & 19 & 45 & 179.257 .273 & 4.273.565.151 & 1.253 .408 .462 & Up & 0.00015929 & 0.00075418 \\
\hline $\begin{array}{l}\text { rno-miR-323- } \\
\text { 3p }\end{array}$ & 86 & 194 & 811.375 .025 & 184.238 .142 & 1.183 .130 .967 & Up & $3.38 \mathrm{E}-14$ & $3.13 \mathrm{E}-13$ \\
\hline $\begin{array}{l}\text { rno-miR-144- } \\
\text { 3p }\end{array}$ & 1247 & 2721 & 1.176 .493 .786 & 2.584 .082 .394 & 1.135 .158 .371 & Up & 2.35E- 168 & $1.06 \mathrm{E}-166$ \\
\hline $\begin{array}{l}\text { sp } \\
\text { rno-miR-6334 } \\
\text { rno-miR-21-3p }\end{array}$ & $\begin{array}{l}43 \\
45\end{array}$ & $\begin{array}{l}91 \\
93\end{array}$ & $\begin{array}{l}4.056 .875 .125 \\
4.245 .566 .991\end{array}$ & $\begin{array}{l}8.642 .098 .415 \\
8.832 .034 .644\end{array}$ & $\begin{array}{l}1.091 .012 .765 \\
1.056 .788 .594\end{array}$ & $\begin{array}{l}\text { Up } \\
\text { Up }\end{array}$ & $\begin{array}{l}9.13 \mathrm{E}-07 \\
1.19 \mathrm{E}-06\end{array}$ & $\begin{array}{l}5.43 \mathrm{E}-06 \\
7.01 \mathrm{E}-06\end{array}$ \\
\hline mo-miR-150- & 2489 & 769 & 2.348 .270 .276 & 7.303 .048 .002 & -1.685 .027 .848 & Down & $5.82 \mathrm{E}-165$ & $2.48 \mathrm{E}-163$ \\
\hline $\begin{array}{l}\text { sp } \\
\text { rno-miR-335 }\end{array}$ & 854 & 267 & 805.714 .269 & 2.535 .648 .656 & -1.667 .913 .449 & Down & $7.23 \mathrm{E}-57$ & $1.39 \mathrm{E}-55$ \\
\hline rno-miR-322- & 1632 & 547 & 1.539 .725 .629 & 5.194 .755 .861 & -156.754 .544 & Down & $1.15 \mathrm{E}-96$ & 3.05E-95 \\
\hline $\begin{array}{l}5 \mathrm{p} \\
\text { rno-miR-184 }\end{array}$ & 867 & 313 & 8.179 .792 .403 & 2.972 .501 .982 & -1.460 .386 .457 & Down & $2.23 \mathrm{E}-46$ & $3.56 \mathrm{E}-45$ \\
\hline $\begin{array}{l}\text { rno-miR-134- } \\
\text { 3p }\end{array}$ & 177 & 73 & 1.669 .923 .017 & 6.932 .672 .355 & -1.268 .298 .112 & Down & $1.44 \mathrm{E}-08$ & $9.76 \mathrm{E}-08$ \\
\hline $\begin{array}{l}\text { rno-miR-139- } \\
5 \mathrm{p}\end{array}$ & 338 & 150 & 318.889 .254 & 1.424 .521 .717 & -1.162 .577 .866 & Down & $5.14 \mathrm{E}-13$ & $4.43 \mathrm{E}-12$ \\
\hline $\begin{array}{l}\text { rno-miR-126a- } \\
3 \mathrm{p}\end{array}$ & 489709 & 220073 & 4.620.205.257 & 2.089.991.785 & -1.144 .459 .674 & Down & 0 & 0 \\
\hline $\begin{array}{l}\text { rno-miR-497- } \\
\text { 3p }\end{array}$ & 112 & 51 & 1.056 .674 .451 & 4.843 .373 .837 & -1.125 .446 .701 & Down & $6.01 \mathrm{E}-05$ & 0.00029554 \\
\hline $\begin{array}{l}\text { rno-miR-203a- } \\
3 \mathrm{p}\end{array}$ & 1384 & 659 & 1.305 .747 .715 & 6.258 .398 .743 & -1.061 .010 .693 & Down & $9.57 \mathrm{E}-41$ & $1.47 \mathrm{E}-39$ \\
\hline $\begin{array}{l}\text { rno-miR-503- } \\
\text { p }\end{array}$ & 428 & 205 & 4.038 .005 .938 & 1.946 .846 .346 & -1.052 .504 .008 & Down & $1.77 \mathrm{E}-13$ & $1.58 \mathrm{E}-12$ \\
\hline
\end{tabular}

\title{
GO enrichment analyses and KEGG enrichment analyses
}

The distribution of GO gene functional groups was used to visually reflect the distribution of differential genes in GO Term, which is rich in biological processes (BP), cellular components (CC), and molecular functions (MF). Figure 4B showed part of the GO enrichment analysis of differentially expressed genes between the hyperoxia group and the normoxia group. The role of KEGG is to study the enrichment of metabolic pathways for differentially expressed genes. Pathway enrichment analysis showed that miRNA was involved in $211 \mathrm{KEGG}$ pathways. The results showed that the enriched KEGG terms were associated with extracellular matrix (ECM)-receptor interaction, cytokine-cytokine receptor interaction, RNA transport, cell cycle, and cell adhesion molecules (Figure 3C).

\section{Confirmation of miRNAs and target genes by qRCR analysis}

\begin{abstract}
MiRNA target gene Prediction software TargetScan (http://www.targetscan.org/vert_71/) was used to predict the target genes of the differentially expressed miRNAs. Four miRNAs and eight of their target genes were selected for the qRCR analysis based on the KEGG pathway analysis. The differentially expressed miRNAs (rno-miR-29b-3p, rno-miR-335, rno-miR-322-5p and rno-miR-203a-3p) were detected. Figure 5 results showed that rno-miR-29b-3p were up-regulated, and rnomiR-322-5p and rno-miR-335 were down-regulated in the hyperoxia sample comparing with the normoxia group, which is consistent with the RNA sequencing data. Meanwhile, the target genes were also detected by qRCR (Figure 4A-4C). The expression of rno-miR203a-3p was increased in the hyperoxia group while decreased in the RNA-seq results (Figure 4D).
\end{abstract}


A

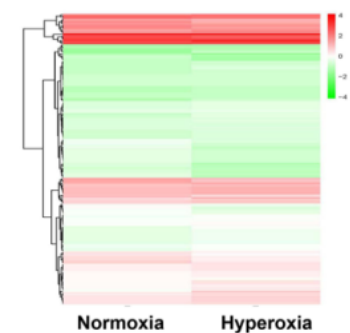

B

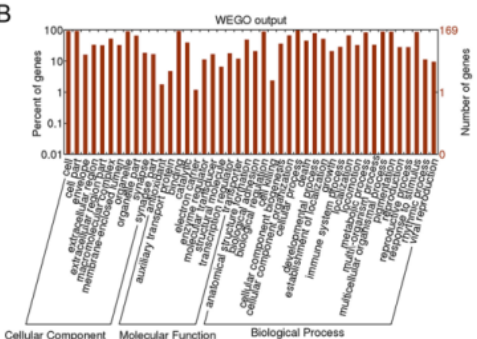

C

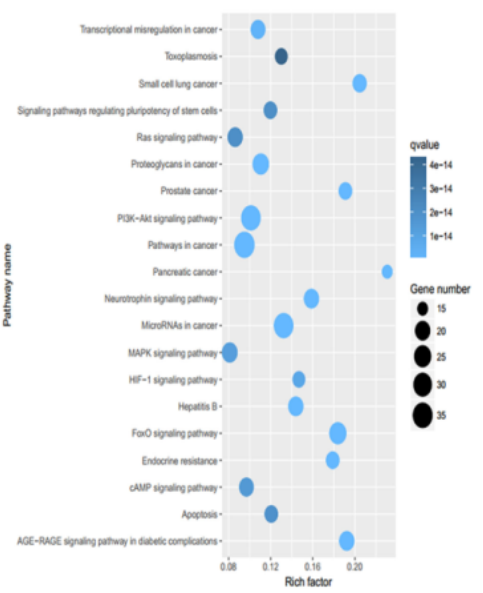

Figure 3. Differentially expressed miRNAs determined using RNA-seq in normoxia and hyperoxia group. A) Cluster graph presented differentially expressed miRNAs. B) GO analysis of the differentially expressed miRNAs. C) KEGG pathway analysis of the differentially expressed miRNAs.

A

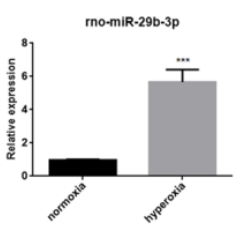

B
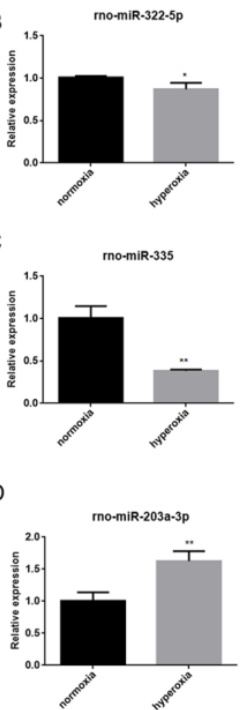
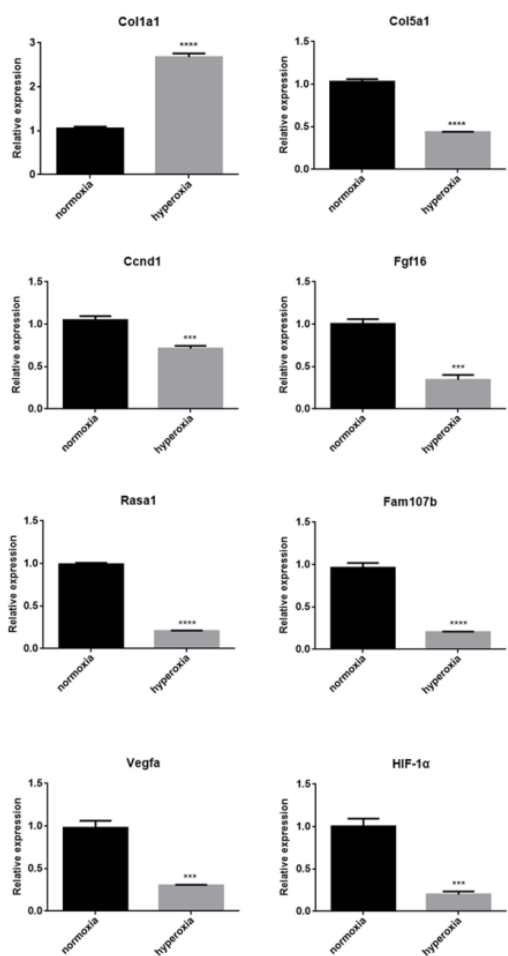

Figure 4. qRT-PCR validates the differentially expressed miRNA in normoxia and hyperoxia group. A) miR-29b-3p and its target genes Colla1 and Col5a1; B) miR-322-5p and its target genes Ccnd1 and Fgfl6; C) rno-miR-335 and its the target genes Rasal and Fam107b; D) miR-203a-3p and its target genes Vegfa and HIF-1 $\alpha .{ }^{*} \mathrm{P}<0.05, * * \mathrm{P}<0.01$, $* * * \mathrm{P}<0.001$ and $* * * * \mathrm{P}<0.0001$ vs Normoxia group. 


\section{DISCUSSION}

BPD is a severe, chronic lung disease in premature babies, with a complicated pathogenesis. Supraphysiological $\mathrm{O}_{2}$ concentrations, mechanical ventilation, and inflammation involve in the development of BPD. Newborn rat who expose to hyperoxia causes inflammation and impaired alveolarization similar with BPD in infants (Trembath et al., 2012). In this study, we successfully established and validated hyperoxia rat model BPD, which is consistent with previous studies (Audic and Claverie, 1997; AlejandreAlcázar et al., 2007; Jackson et al., 2016).

MiRNAs are non-coding small RNAs of about 22 nucleotides that regulate gene expression in animals and plants (Bartel, 2004). By binding to the 3 ' untranslated region of target mRNA, miRNAs can interact with specific mRNA, leading to RNA degradation or translational inhibition (Nilsen, 2007; Pritchard et al., 2012). In general, miRNAs are involved in a series of biological processes such as growth, development, organogenesis, tissue differentiation, regeneration, reproduction, endocrine activity and immune response (Boss et al., 2011; Bizuayehu et al., 2014). Aberrant miRNA expression patterns are often associated with the body's disease or disease characteristics (Beermann et al., 2016; Varamo et al., 2017). For example, Roy et al. (2009) described changes in miRNA expression in response to myocardial infarction in the mouse heart, showing that miR-21 regulates metalloprotease-2 via phosphatase and tensin homologue. Recently, Dong et al. (2012) showed the miRNA-mRNA interactions in a murine model of hyperoxia-induced BPD. Therefore, miRNAs can be used as biomarkers for certain diseases. In addition, our previous studies have demonstrated several novel circular RNAs, which may be associated with the pathophysiology of BPD (Cheng et al., 2020). To identify the miRNAs participated in the BPD, the expression profiles of the miRNAs were examined at 14 days. Our study showed that prolonged hyperoxia alters miRNA expression in the neonatal rat lung. DEGseq was used for the selection of differential expression, we found the expression of miRNA between hyperoxia bronchopulmonary dysplasia model and normoxia group was different. A total of 20 different miRNAs were detected in the hyperoxia group and the normoxia group, among which 10 were up-regulated and 10 were down-regulated. Furthermore, pathway enrichment analysis indicated that miRNA was involved in 211 KEGG pathways. The results showed that ECM-receptor interaction, cell cycle, TGF- $\beta$ signaling pathway and vascular endothelial growth factor signal pathway were associated with the KEGG terms. We found that one miRNA could target many genes. This suggests that the miRNA may involve in a series of biological processes. Studies have also reported that some miRNAs are participated in many biological events (Lu et al., 2005; Beermann et al., 2016). Therefore, there may be a connection between the BPD and these GO terms or pathways.

MiR-29b-3p is associated with fibrosis, immunity, osteoarthritis and tumors. Among the target genes of mo-miR-29b-3p, Colla1 and Col5al are genes directly related to collagen. The association between collagen type I alpha 1 chain (Cola1), collagen type V alpha 1 chain (Col5a1) and rno-miR-29b-3p has been reported (Chen et al., 2015; Lu et al., 2016). qRCR results showed that the target gene Colal of rno-miR-29b-3p was upregulated in rat lung tissue of hyperoxia group, while the expression of Col5al was downregulated and the expression of miR-29-3p was up-regulated compared with the normal group. It has been reported that subepithelial collagen increased in BDP models (Royce et 
al., 2016). miR-322-5p is associated with inflammatory response and tumor. The target gene of rno-miR-322-5p is Cyclin D1 (Ccnd1), which regulates the cell cycle; fibroblast growth factor 16 (Fgf16) is fibroblast growth factor. Both Ccnd1 and Fgf16 in the lung tissue of hyperoxia group were down-regulated compared with the normal group. Ccnd1 is highly expressed and growth factors changed as reported in BPD models (Bhattacharya et al., 2014), while our results is low expression, and miR-322-5p is low expression. miR-335 is associated with proliferation and differentiation of mesenchymal stem cells and bone formation. The target gene of rno-miR-335 is RAS P21 protein activator 1 (Rasa1), which is involved in RasGTPase mediated signal transduction and cell proliferation migration. The expression of rno-miR-335 was down-regulated in the lung tissue of BDP rats, and RasGTPase play an important role in mediating cell and matrix proliferation (de la Pena et al., 2014; Carrera et al., 2015). In our study, Rosal and family with sequence similarity 107 member B in hyperoxia group were down-regulated compared with the normal group. MiR335 is also low expression. The results of qRCR is more reliable. Therefore, the reliability and accuracy of the RNA sequencing data were confirmed by qRCR analysis.

In conclusion, we have shown that miRNAs may be involved in the development of BPD. Our study provides new insight into understanding the biological processes of BPD.

\section{ACKNOWLEDGMENTS}

The authors thanks CAPES- Coordenação de Aperfeiçoamento de Pessoal de Nível Superior and FAPESP-Fundação de Amparo à Pesquisa do Estado de São Paulo for financial support.

\section{AUTHORS' CONTRIBUTIONS}

Dongcai Li and Hanrong Cheng performed all the experiments, analyzed the data, and wrote the manuscript. Benqing Wu participated in the design of the experiments and manuscript revision. Li Chen helped to carry out the HE staining. All authors read and approved the final manuscript.

\section{FUNDING}

This work was supported by grants from the Shenzhen science and technology innovation project of China (JCYJ20140416122812046) and Guangdong Medical Science and Technology Research Fund Project, China (B2018172).

\section{ETHICS APPROVAL AND CONSENT TO PARTICIPATE}

The study was approved by the Institute Research Medical Ethics Committee of Shenzhen Peoples' Hospital. All animal experiments were conducted according to relevant national and international guidelines.

\section{CONFLICTS OF INTEREST}

The authors declare no conflict of interest. 


\section{REFERENCES}

Alejandre-Alcázar MA, Kwapiszewska G, Reiss I, Amarie OV, et al. (2007). Hyperoxia modulates TGF- $\beta$ /BMP signaling in a mouse model of bronchopulmonary dysplasia. Am. J. Physiol. Lung Cell Mol. Physiol. 292: L537L549.

Ameis D, Khoshgoo N, Iwasiow BM, Snarr P, et al. (2017). MicroRNAs in Lung Development and Disease. Paediatr. Respir. Rev. 22: 38-43.

Audic S and Claverie J-M (1997). The significance of digital gene expression profiles. Genome Res. 7: 986-995.

Bartel DP (2004). MicroRNAs: genomics, biogenesis, mechanism, and function. Cell. 116: 281-297.

Beermann J, Piccoli M-T, Viereck J and Thum T (2016). Non-coding RNAs in development and disease: background, mechanisms, and therapeutic approaches. Physiol. Rev. 96: 1297-1325.

Bhattacharya S, Zhou Z, Yee M, Chu C-Y, et al. (2014). The genome-wide transcriptional response to neonatal hyperoxia identifies Ahr as a key regulator. Am. J. Physiol. Lung Cell Mol. Physiol. 307: L516-L523.

Bizuayehu TT, Babiak I, (2014). MicroRNA in teleost fish. Genome Biol. Evol. 6: 1911-1937.

Boss IW, Renne R, (2011). Viral miRNAs and immune evasion. Biochim Biophys. Acta Gene Regul. Mech. 1809: 708714.

Carrera P, Di Resta C, Volonteri C, Castiglioni E, et al. (2015). Exome sequencing and pathway analysis for identification of genetic variability relevant for bronchopulmonary dysplasia (BPD) in preterm newborns: a pilot study. Clin. Chim. Acta. 451: 39-45.

Chen Y, Mohammed A, Oubaidin M, Evans CA, et al. (2015). Cyclic stretch and compression forces alter microRNA-29 expression of human periodontal ligament cells. Gene. 566: 13-17.

Cheng H, Wu B, Wang L, Hu T, et al. (2020). Insights into the expression profiles and functions of circRNAs in a newborn hyperoxia-induced rat bronchopulmonary dysplasia model. J. Gene Med. 22: e3163.

Choi CW, Lee J, Lee HJ, Park H-S, et al. (2015). Deferoxamine improves alveolar and pulmonary vascular development by upregulating hypoxia-inducible factor- $1 \alpha$ in a rat model of bronchopulmonary dysplasia. J. Korean Med. Sci. 30: 1295-1301.

de la Pena, FA, Kanasaki K, Kanasaki M, Vong S, et al. (2014). Specific activation of K-RasG12D allele in the bladder urothelium results in lung alveolar and vascular defects. PloS One. 9: e95888.

Dong J, Carey WA, Abel S, Collura C, et al. (2012). MicroRNA-mRNA interactions in a murine model of hyperoxiainduced bronchopulmonary dysplasia. BMC Genomics. 13: 204.

Durrani-Kolarik S, Pool CA, Gray A, Heyob KM, et al. (2017). miR-29b supplementation decreases expression of matrix proteins and improves alveolarization in mice exposed to maternal inflammation and neonatal hyperoxia. Am. J. Physiol. Lung Cell Mol. Physiol. 313: L339-1349.

Jackson W and Laughon MM (2016). Biomarkers of Bronchopulmonary Dysplasia, Bronchopulmonary Dysplasia. Springer, pp. 129-148.

Kobaly K, Schluchter M, Minich N, Friedman H, et al. (2008). Outcomes of extremely low birth weight $(<1 \mathrm{~kg})$ and extremely low gestational age ( $<28$ weeks) infants with bronchopulmonary dysplasia: effects of practice changes in 2000 to 2003. Pediatrics. 121: 73-81.

Lal CV, Olave N, Travers C, Rezonzew G, et al. (2018). Exosomal microRNA predicts and protects against severe bronchopulmonary dysplasia in extremely premature infants. JCI Insight. 3.

Lu J, Getz G, Miska EA, Alvarez-Saavedra E, et al. (2005). MicroRNA expression profiles classify human cancers. Nature. 435: 834.

Lu Y-F, Liu Y, Fu W-M, Xu J, et al. (2016). Long noncoding RNA H19 accelerates tenogenic differentiation and promotes tendon healing through targeting miR-29b-3p and activating TGF- $\beta 1$ signaling. FASEB J. 31: 954-964.

Niedermaier S and Hilgendorff A (2015). Bronchopulmonary dysplasia-an overview about pathophysiologic concepts. Mol. Cell Pediatr. 2: 2.

Nilsen TW (2007). Mechanisms of microRNA-mediated gene regulation in animal cells. Trends Genet. 23: 243-249.

Pritchard CC, Cheng HH and Tewari M (2012). MicroRNA profiling: approaches and considerations. Nat. Rev. Genet. 13: 358.

Roy S, Khanna S, Hussain SR, Biswas S, et al. (2009). MicroRNA expression in response to murine myocardial infarction: miR-21 regulates fibroblast metalloprotease-2 via phosphatase and tensin homologue. Cardiovasc. Res. 82: $21-29$.

Royce SG, Nold MF, Bui C, Donovan C, et al. (2016). Airway remodeling and hyperreactivity in a model of bronchopulmonary dysplasia and their modulation by IL-1 receptor antagonist. Am. J. Respir. Cell Mol. Biol. 55: 858-868.

Syed M, Das P, Pawar A, Aghai ZH, et al. (2017). Hyperoxia causes miR-34a-mediated injury via angiopoietin-1 in neonatal lungs. Nat. Commun. 8: 1173.

Trembath A, Laughon MM, (2012). Predictors of bronchopulmonary dysplasia. Clin. Perinatol. 39: 585-601.

Varamo C, Occelli M, Vivenza D, Merlano M, et al. (2017). MicroRNAs role as potential biomarkers and key regulators in melanoma. Genes. Chromosomes Cancer. 56: 3-10. 
Yang Y, Qiu J, Kan Q, Zhou XG, et al, (2013). MicroRNA expression profiling studies on bronchopulmonary dysplasia: a systematic review and meta-analysis. Genet. Mol. Res. 12: 5195-5206.

You K, Xu X, Fu J, Xu S, et al. (2012). Hyperoxia disrupts pulmonary epithelial barrier in newborn rats via the deterioration of occludin and ZO-1. Respir. Res. 13: 36.

Zhang Y, Dong X and Lingappan K (2019). Role of HIF-1 $\alpha$-miR30a-Snai1 Axis in Neonatal Hyperoxic Lung Injury. Oxid. Med. Cell Longev. 2019: 8327486.

Zhu Y, Fu J, Yang H, Pan Y, et al. (2015). Hyperoxia-induced methylation decreases RUNX3 in a newborn rat model of bronchopulmonary dysplasia. Respir. Res. 16: 75. 